\title{
Abstracts of Award-Winning Posters, 12th Annual Health Sciences Poster Conference, Faculty of Medicine, Health Sciences Centre, Kuwait University, Kuwait, April 16-18, 2007
}

\section{Dr. Nael Al-Naqeeb Award for Best Undergraduate Research}

\section{Serum Adiponectin Level among Healthy Subjects: Relationship to Glucose and Family History of Diabetes Mellitus}

A. Al Sharafi, A. Al Farra, A. Abdulla, S. George, N.A. Abdella, O.A. Mojiminiyi

Departments of Medicine and Pathology, Kuwait University Faculty of Medicine, Kuwait

Introduction: Adiponectin is a recently discovered adipocytederived hormone that has been proposed to play a significant role in the comorbidities associated with obesity. The aim of our study was to explore the relationship between serum adiponectin level and anthropometric and metabolic parameters in apparently healthy subjects. Materials and Methods: Fifty-eight healthy male subjects with mean ( $95 \%$ confidence interval, CI) body mass index (BMI) of 25 (22.98-27.49) and 53 patients with type 2 diabetes mellitus (T2DM) and BMI of 26.38 (22.23-30.52) were recruited into this study. Anthropometric measurements (height, weight, BMI, waist circumference), blood pressure and family history of diabetes in parents, siblings and relatives were recorded. Fasting serum adiponectin, insulin and plasma glucose, lipid profiles, and uric acid levels were measured. Results: Adiponectin showed significant inverse correlations with indices of obesity in patients with T2DM but not in healthy subjects. Adiponectin also showed significant negative correlation $(\mathrm{r}=-0.28 ; \mathrm{p}=0.03)$ with glucose in healthy subjects. In healthy subjects, the mean $(95 \% \mathrm{CI})$ adiponectin in those without family history of diabetes [20.32 $(16.73-23.90) \mathrm{mg} / \mathrm{ml}$ ] was significantly higher than in healthy subjects with a family history of diabetes $[16.33(14.26-18.40) \mathrm{ng} /$ $\mathrm{ml}$ ] and patients with T2DM [15.80 (14.25-17.36) mg/ml] $(\mathrm{p}<$ 0.05 ). When patients were grouped according to family history of diabetes, the lowest adiponectin was found in patients with a history of T2DM in both parents (father and mother). Conclusions: This study shows that adiponectin is inversely related to fasting glucose in healthy subjects. Our results also suggest that plasma adiponectin concentration may be a convenient marker for identifying healthy subjects who may be at risk of developing T2DM. Longitudinal studies are required to confirm this potential application of adiponectin.

\section{Best Postgraduate Awards}

\section{Basic Sciences (MSc)}

\section{Effect of Mn-Porphyrin on Antioxidant Enzymes in Diabetic Rat Kidney}

D. Ali, J.D. Craik, L. Benov

Department of Biochemistry, Kuwait University, Faculty of Medicine, Kuwait

Introduction: Diabetic nephropathy is the single most common disorder leading to renal failure. Recent data suggest that diabetic nephropathy is a consequence of hyperglycemia-induced oxidative stress. Under normal circumstances, the kidney generates reactive oxygen species, which are efficiently eliminated by superoxide dismutase (SOD), catalase, and glutathione peroxidase (GPX). Oxidative stress occurs when reactive oxygen species production overrides the capacity of the antioxidant defense. The aim of this study was to investigate the effect of an Mn-porphyrin SOD mimic, MnTMPyP, on the activities of the antioxidant enzymes SOD, catalase, GPX, and glutathione reductase (GR) in the kidneys of streptozotocin (STZ) hyperglycemic (HG) rats. Materi-

\section{KARGER}

Fax +41613061234

E-Mail karger@karger.ch

www.karger.com
(C) 2007 S. Karger AG, Basel

1011-7571/07/0165-0402\$23.50/0

Accessible online at:

www.karger.com/mpp 
als and Methods: Female Wistar rats were injected i.p. with STZ $(60 \mathrm{mg} / \mathrm{kg})$. Rats which maintained blood glucose concentrations above $15 \mathrm{~mm}$ in the 1 st week were divided into 2 groups designated as 'HG' and 'HG + MnTMPyP'. The animals in the second group received s.c. injection of sterile $\mathrm{MnTMPyP}$ solution, $1 \mathrm{mg} /$ $\mathrm{kg} /$ day for 2 months. After 2 months rats were sacrificed, and kidney homogenates were used for determination of SOD, catalase, GPX and GR activities. Results: Compared to the normoglycemic controls, SOD and GPX were markedly elevated in the STZ rats, while catalase and GR remained unaffected. Treatment with MnTMPyP further elevated the SOD (statistically insignificant), GR and catalase activities, but had no effect on GPX. Conclusions: The increase in the activities of the antioxidant enzymes is a physiological response aimed at protecting the tissues against hyperglycemia-induced oxidative stress. The effect of MnTMPyP can be interpreted in different ways: (a) it protects the enzymes against hyperglycemia-induced inactivation; (b) in the assays, the intrinsic MnTMPyP catalytic activity adds to the activities of the rat enzymes; (c) MnTMPyP acts as a pro-oxidant. Further detailed studies are needed to distinguish between those possibilities.

\section{Basic Sciences (PhD)}

\section{Variability in Hepatitis B Virus Core Sequence Associated with Persistence of Viral Replication and Changes in T-Cell Responses}

\author{
M.M. Ali ${ }^{\text {a }}$, F. Al-Ali ${ }^{\text {b, c }, ~ S . ~ A h m a d ~}{ }^{\text {a }}$, W. Al-Nakib ${ }^{\text {a }}$ \\ Departments of a Microbiology and ${ }^{\mathrm{b}}$ Medicine, Kuwait \\ University Faculty of Medicine; 'Department of \\ Gastroenterology, Mubarak Al-Kabeer Hospital, Kuwait
}

Introduction: Hepatitis B virus DNA contains four open reading frames. The core gene encodes the 185 amino acid long nucleocapsid protein $(\mathrm{HBcAg})$ and the nonparticulate form identified as HBeAg. HBcAg is an immunologic target of CTL that contains helper T-cell and humoral epitopes. Different HLArestricted $\mathrm{HBcAg} \mathrm{T}$-cell epitopes have been proposed. Recently, substitutions in the amino acid sequence of the $\mathrm{HBcAg}$ were reported which are related to viral persistence and active liver disease. The aim of this study was to identify these substitutions and their influence on the progression of liver disease among HBV chronically infected patients in Kuwait. Materials and Methods: Sera samples were collected from $100 \mathrm{HBV}$ chronically infected patients. The complete HBV core gene was amplified and sequenced. Precore and basal core promoter mutations affecting the $\mathrm{HBeAg}$ expression and enhancing viral replication were detected. Different CD4 and CD8 T-cell epitopes were characterized. Finally, the phylogenetic relationship was analyzed using Phylip program. Results: HBV genotype/subtype-specific nucleotide substitutions were found characterizing genotypes $\mathrm{A}, \mathrm{D}, \mathrm{A}+\mathrm{D}$ and C/D hybrids. CD4 T-cell epitope (amino acids 147-156) identified a major target in HLADR13 has been examined with a mutation at position 151 essential for T cell recognition. HLA-(A2, A24, $\mathrm{A} 31$ and A11) were found restricted to the CD8 epitopes. The most prevalent precore mutation is G1896A and basal core promoter mutations are A1762T and G1764A. Conclusions: Most amino acid substitutions involved the HLA-restricted CTL, T-helper and B-cell epitopes, irrespective of HBV genotype/subtype. Specific precore/basal core promoter mutants and T-cell epitopes were found which may affect the severity of the liver disease within the local population.

Funding Agency: Supported by Research Administration project grants YM 02/03, Kuwait.

\section{Resident}

\section{Microsatellite Instability Analysis in Colorectal Cancer: Why Are Our Patients So Young?}

N. Hamadi a, W. Al-Ali ${ }^{\text {b }}$, J. Patrick ${ }^{\text {h }}$, A. Odi h, S. Al-Fadhli ${ }^{\text {, }}$

S. Abdeen ${ }^{\text {b }}$, B. Al-Ayadhi b A. Behbehani ' , A. Mathew ${ }^{\text {c, }}$

T. Al-Ajrawi ' , M. Farghali ', A. Al-Mahrous ${ }^{\mathrm{f}}$, S. Al-Awadi',

A. Al-Asfour ${ }^{9}$, F. Al-Mulla ${ }^{\text {b }}$

${ }^{a}$ College of Graduate Studies, Kuwait University,

Departments of bPathology and 'Surgery, Faculty of Medicine, Kuwait University, dFarwania Hospital, eAdan Hospital,

${ }^{f}$ Mubarak Al-Kabeer Hospital, ${ }^{9} \mathrm{KCC}$ Hospital, h Amiri Hospital,

'Faculty of Allied Health, Kuwait University, Kuwait

Introduction: Colorectal Cancer (CRC) is a common disease that affects both men and women. It is the third most common cause of cancer-related deaths in the Western world. The incidence rate of CRC in Kuwait is 8/100,000/year. CRC is classified as sporadic or inherited. CRC affects young patients in Kuwait and virtually nothing is known about the role of mismatch repair genes (MLH1, MSH2, and MSH6) in CRC in this population. This study aims to evaluate major molecular pathways with particular emphasis on the role of mismatch repair genes and microsatellite instability (MSI) on the pathogenesis of CRC in Kuwait. Materials and Methods: 158 colorectal cancer samples were randomly selected from major hospitals in Kuwait and tested for mismatch repair protein expression by immunohistochemistry in which prepared paraffin-embedded tumor tissue slides were stained with antibodies against three mismatch repair gene proteins (MLH1, MSH2 and MSH6), then scored for the presence or absence of each protein. MSI was determined for tumor samples and their matched normal by amplifying five DNA microsatellite regions (BAT-25, BAT-26, D2S123, D5S346 and D17S250) using PCR. Products were analyzed by gel electrophoresis and levels of instability were determined. Results: MSI represents a major cause of CRC in this population. We show, for the first time, that loss of MLH1 mismatch repair axis plays a significant role in CRC development in Kuwait. MSI was associated with young age, right sided and poorly differentiated CRCs. Conclusions: This is the first and largest study that has been undertaken in the Gulf area. Our results show high prevalence of mismatch repair gene defect in CRC patients, which can explain the young age at onset of this disease in Kuwait. If confirmed, an association with hereditary nonpolyposis colorecal cancer should be determined in the near future.

Funding Agency: Terry Fox Foundation - Project No. $\mathrm{TFF} / 04 / 05$. 


\section{Basic and Applied Sciences Award}

\section{1 \\ The Nonselective Adenosine Receptor Agonist 5-N-Ethylcarboxamidoadenosine Induces both Proinflammatory and Anti-Inflammatory Effects in Mice}

\author{
A.Z. El-Hashim ${ }^{\mathrm{a}}$, H.T. Abduo ${ }^{\mathrm{a}}$, O.M. Rachid ${ }^{\mathrm{a}}$, B.Y. Al Aydhy ${ }^{\mathrm{b}}$ \\ aDepartment of Applied Therapeutics, Faculty of Pharmacy, \\ and ${ }^{\mathrm{b}}$ Department of Pathology, Faculty of Medicine, \\ Kuwait University, Kuwait
}

Introduction: The role of adenosine in asthma is inconclusive. Whilst some studies have shown that adenosine is a bronchoconstrictor and proinflammatory mediator, others have suggested that adenosine has anti-inflammatory actions. Materials and Methods: In this study, we have investigated (1) the effects of NECA on airway cellular influx in intraperitoneally ovalbumin (OVA)-immunized mice and (2) its effects on intranasal (i.n.) OVA-induced cell influx in immunized mice. All mice were immunized with OVA in alum on day 0 . To assess the effects of NECA on immunized mice, animals were treated with NECA (0.1-1 mM) or vehicle ( $\mathrm{n}=6-7$ per group) on days 10 and 11 , and bronchoalveolar lavage was performed on day 13 . To assess the effects of NECA on OVA-induced inflammation, mice were challenged with OVA or PBS (i.n.), and then treated with NECA (0.3 $\mathrm{mM}$; i.n.) 5-10 min later, on days $10,11,12$ and 13 ( $\mathrm{n}=10-12)$. Bronchoalveolar lavage was performed on day 15. Results: In immunized mice, NECA administration caused a pronounced neutrophilia at $1 \mathrm{mM}$ compared to vehicle $\left(4.1 \times 10^{4}+1.7 \times 10^{4}\right.$ cells $/ \mathrm{ml}$ vs. $0.6 \times 10^{4}+0.3 \times 10^{4}$ cells $\left./ \mathrm{ml} ; \mathrm{p}<0.05\right)$. Intranasal OVA challenge induced a significant increase in both neutrophil $\left(32.2 \times 10^{4}+9.4 \times 10^{4}\right.$ cells $/ \mathrm{ml}$ vs. $0.7 \times 10^{4}+0.4 \times 10^{4}$ cells $/ \mathrm{ml}$; $\mathrm{p}<0.05)$ and eosinophil $\left(44.7 \times 10^{4}+10.9 \times 10^{4}\right.$ cells $/ \mathrm{ml}$ vs. 0.03 $\times 10^{4}+0.03 \times 10^{4}$ cells $\left./ \mathrm{ml} ; \mathrm{p}<0.05\right)$ counts. Treatment with NECA significantly reduced both OVA-induced neutrophil (6.4 $\times 10^{4}+2.2 \times 10^{4}$ cells $/ \mathrm{ml}$ vs. $32.2 \times 10^{4}+9.4 \times 10^{4}$ cells $/ \mathrm{ml}$; $\mathrm{p}<0.05)$ and eosinophil $\left(11.1 \times 10^{4}+4.0 \times 10^{4}\right.$ cells/ml vs. 44.7 $\times 10^{4}+10.9 \times 10^{4}$ cells/ml; $\left.\mathrm{p}<0.05\right)$ influx. Conclusions: These results show that, in immunized but not challenged mice, NECA can induce a mild neutrophilic inflammation. However, when given together with a strong inflammatory stimulus, NECA can induce significant anti-inflammatory effects.

\section{2 \\ Nitric Oxide-Induced Activation of NOX in Human Dermal Fibroblasts Is Attenuated by Insulin-Transferrin-Selenium}

M. Alsaeid ${ }^{\text {a }}$, G.S. Dhaunsi ${ }^{\text {a }}$, J. Kaur ${ }^{\text {C, M.S. Bitar }}{ }^{\text {b }}$

Departments of a Pediatrics and bPharmacology, Faculty of Medicine, Kuwait University, Kuwait; ' $\mathrm{C}$ epartment of Pediatrics, University of Virginia, Charlottesville, Va., USA

Introduction: Nitric oxide (NO) has significance in all the fields of biology and medicine including diseases of children, and several cellular functions are regulated by NO through its actions as an intracellular signaling molecule. NO is also known to regulate the levels of superoxide anion, either through direct interactions or via its effect on NADPH oxidase (NOX). We have investigated the antioxidant effects of insulin-transferrin-selenium (ITS), a unique metalloprotein complex on NO-mediated activation of NOX in human dermal fibroblasts. Methods: Human dermal fibroblasts grown from skin explants were cultured in growth medium. Cell cultures were treated with S-nitroso-N-acetylpenicillamine (SNAP; a NO donor, 100-500 $\mu \mathrm{M}$ ), apocynin (APO; a NOX inhibitor, $1 \mathrm{mM}$ ) and/or ITS (10 U/100 ml medium). NOX activity was measured in cell homogenates. Total RNA was extracted for RT-PCR analysis of NOX-1, PPAR- $\gamma$, IGF-1 and GAPDH. Results: Treatment of cell cultures with SNAP significantly $(\mathrm{p}<0.01)$ increased the NOX activity. SNAP-induced NOX enzyme activity was significantly $(\mathrm{p}<0.05)$ reduced by both ITS and APO. Gene expression of NOX-1 and IGF-1 was markedly (2to 3-fold) elevated by SNAP, whereas ITS significantly downregulated the mRNA levels of both NOX-1 and IGF-1. However, ITS failed to block the SNAP-induced increase in mRNA levels of IGF1. APO was also observed to markedly downregulate the SNAPinduced enhancement of NOX-1 and IGF-1 mRNA levels. SNAP was found to markedly elevate gene expression of PPAR- $\gamma$ irrespective of the presence of APO. Although ITS did not alter mRNA levels of PPAR- $\gamma$, it significantly reduced SNAP-induced activation. Conclusions: We report for the first time a NO-induced activation of IGF-1 which, at least in part, is NOX mediated, and the inhibitory effect of ITS on NO-mediated activation of NOX leads us to a conclusion that the ITS complex is an antioxidant which might be useful in blocking NOX-mediated cellular oxidative stress. 


\section{Clinical Sciences Awards}

\section{1}

\section{APOE Genetic Polymorphism in Relation to Blood Levels of Homocysteine and C-Reactive Protein in Arab Schizophrenic Patients}

A.O. Akanji ${ }^{\text {a }}$, J.U. Ohaeri ${ }^{\text {d }}$, S. Al-Shammri ${ }^{\text {b }}$, H.R. Fatania ${ }^{\text {, }}$, A. Bhattacharya ${ }^{a}$

Departments of a Pathology, ${ }^{\mathrm{b}}$ Medicine and ${ }^{\mathrm{C} B i o c h e m i s t r y,}$ Kuwait University Faculty of Medicine, and ${ }^{\mathrm{d}}$ Psychological Medicine Hospital, Kuwait

Introduction: Schizophrenia (SZ), a complex genetic disorder, is an important cause of psychiatric morbidity and handicap in the Arabian Gulf Region. There is some evidence that APOE polymorphism may play a role in the pathogenesis of SZ and its clinical phenotype. This study extends our previous observations on APOE allelic frequencies in SZ and investigates the influence of APOE polymorphism on blood markers of oxidative damage (homocysteine, tHcys) and persisting inflammation (high-sensitivity C-reactive protein, hsCRP) in Arab patients with SZ. Materials and Methods: Two groups of age-, BMI- and WHR-matched subjects were studied: (1) 207 SZ patients, on follow-up at the Psychiatric Hospital; (2) 165 apparently healthy control (HC) subjects recruited from the Central Blood Bank. Fasting blood samples were collected from each subject and analyzed for serum tHcys and hsCRP by automated ELISA (IMMULITE ${ }^{\circledR} 1000$ Analyzer). APOE genotyping was done for all the subjects by validated PCR/ restriction enzyme digestion methods. Results: APOE genotype E3E2 and allele E2 were more frequent in $\mathrm{HC}$ than in SZ, $\mathrm{p}<0.01$. Similarly, blood tHcys and hsCRP levels were higher in SZ than in $\mathrm{HC}$, as expected, and weakly correlated with each other in both groups $(r=0.10, p=0.08)$. In both the SZ and HC groups, the APOE allelic pattern had no influence on tHcys levels. However, in the SZ group but not the controls, CRP levels were highest with E2 $(\mathrm{p}<0.01)$ and also differed between E3 and E4, being higher with E4 ( $\mathrm{p}=0.05)$. Conclusions: APOE allele E2 seems to protect against SZ, being significantly commoner in healthy controls than in patients with SZ. Persisting inflammation in SZ, as indicated from hsCRP levels, appears more pronounced with E2 and is lowest in E4, although tHcys, as an index of oxidative damage, did not appear to be influenced by APOE polymorphism. These observations require further evaluation in a clinical context.
Metafer4-PV, the Optimal Fluorescence in situ Hybridization Scoring System for her-2/Neu Amplification in Breast Carcinomas

S.P. Jacob ${ }^{\text {a }}$, F. Al Mulla ${ }^{\text {a }}$, I.M. Francis ${ }^{a}$, A. Al Asfour ${ }^{b}$, S. Al Awadhi ${ }^{\text {b }}$

aDepartment of Pathology, Faculty of Medicine, Kuwait University, bHussain Makki Al-Juma Center for Specialized Surgery, Ministry of Health, Kuwait

Introduction: Twenty to thirty percent of breast cancers show Her-2/neu protein expression and are associated with poor prognosis. A very expensive drug, Herceptin (generic name trastuzumab), has shown great promise by increasing survival time for women with Her-2/neu overexpressed breast carcinomas. FISH offers most accurate, reliable and reproducible results of Her-2/ neu assessment. Discordance between immunohistochemistry (IHC) and FISH is mainly observed in tumors that are moderately positive (2+). Further evaluation by FISH is recommended for such cases before instituting therapy. We developed the first FDA-approved Metafer4-PV software for scoring Her-2/neu gene amplification. Materials and Methods: A total of 37 cases from HMJCSS hospital were received with a median age of 52 years ranging from 31-73 years. Seventy-three percent (27/37) of the cases received were selected as $2+$ by IHC. Five-micrometer-thick tumor tissue sections mounted on silanized slides were subjected to FISH assay using Vysis Path Vysion Probe containing a mixture of spectrum orange-labeled Her-2/neu locus and spectrum green-labeled CEP17 region. Her-2/neu/CEP17 ratios were determined. Cases were categorized as nonamplified, borderline amplified and amplified if the ratios were below 1.8, between 1.8 and 2.2 and above 2.2, respectively. Results: Sixty-five percent $(24 / 37)$ of the cases were nonamplified, $8 \%(3 / 37)$ borderline amplified and 27\% (10/37) amplified for Her-2/neu gene using FISH assay. Among 2+ (IHC) cases, 70\% (19/27) proved to be nonamplified, $7 \%(2 / 27)$ were borderline amplified and $22 \%(6 / 27)$ were amplified. Conclusions: The use of FDA-approved Metafer4-PV system is highly recommended for the optimal scoring of Her-2/neu/ CEp17 ratio determination, which does not depend on the subjective assessment of the pathologist. Our results caution against the use of immunohistochemistry for detection of Her-2/neu gene abnormalities.

Funding Agency: KFAS 990707, Ministry of Health, Kuwait. 


\section{Case Report Award}

\section{Unusual Malignant Transformation of Recurrent Sebaceoma}

H. Al-Khashnam, H. Burezq, I. Al-Aradi, H. Al-Sabah, K. Al-Abdulhadi

Al-Babtain Center for Burns and Plastic Surgery, Asaad Al-Hamad Dermatology Center, Sabah Hospital for Head and Neck and ENT Surgery, Sabah Health Area, Kuwait

Background: Sebaceoma is a benign tumor composed of incompletely differentiated sebaceous cells of varying degrees of maturity. Sebaceomas have never been reported as a known premalignant lesion. Case Summary: This is a report of an 18-yearold boy who presented with a malignant transformation of a recurrent sebaceoma which was excised twice by Moh's surgery. Excision was done with a free margin of $1 \mathrm{~cm}$ down to the parotid fascia. Reconstruction was performed on the same set by using cervicofacial flap extending down to the supraclavicular area. The patient had an uneventful postoperative period apart from distal marginal necrosis of the flap, which healed well with conservative measures and daily dressing, and was sent to our Cancer Centre to start his adjuvant radiotherapy. Conclusion: Previous literature stated that sebaceoma is a distinctive benign tumor. We have presented a case of an unusual malignant transformation of a preauricular recurrent sebaceoma. This indicates that sebaceoma does have a potential risk of malignant transformation. We believe that managing recurrent sebaceoma more aggressively with wide local excision and postoperative adjuvant radiotherapy would provide better prognosis. 